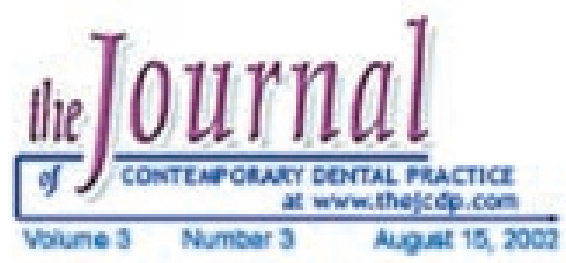

\title{
Reducing Bacterial Counts in Dental Unit Waterlines: Tap Water vs. Distilled Water
}

James D. Kettering, PhD; Joni A. Stephens, RDH, EdS; Carlos A.

Muñoz-Viveros, DDS, MSD; W. Patrick Naylor, DDS, MPH, MS

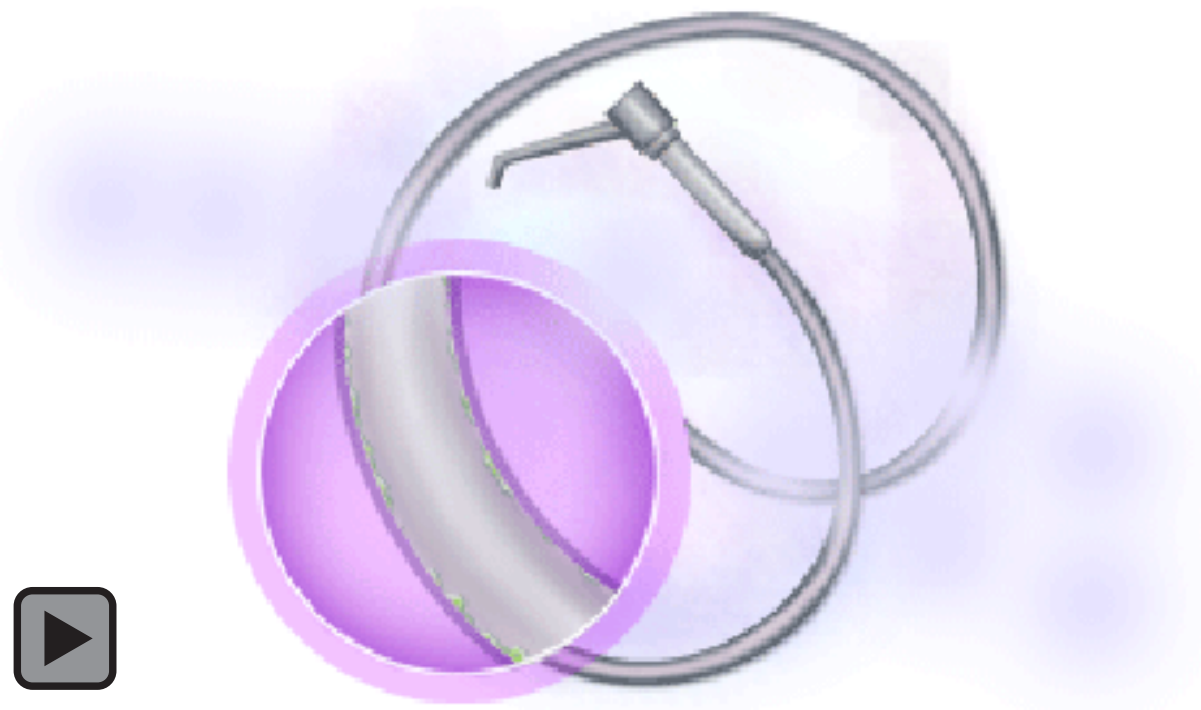

Abstract

Background: The maximum recommended level of microbial contamination of water from dental unit waterlines (DUWL) is 200 colony-forming units per milliliter (CFU/mL). This article addresses the importance of water selection in achieving that standard.

Methods: Microbial contamination in water samples from 75 new dental units, with a closedcircuit water system, were compared using combinations of tap water and sterile distilled water with and without two chemical disinfectants (bleach and $0.12 \%$ chlorhexidine gluconate, Bio2000) over a six-week period. Baseline tap water samples were collected and tested initially.

Results: The microbial plate counts of seven tap water specimens (controls) ranged from 4 to $95 \mathrm{CFU} / \mathrm{mL}$. These results were well below both the $500 \mathrm{CFU} / \mathrm{mL}$ standard for public drinking water and the $200 \mathrm{CFU} / \mathrm{mL}$ goal for dental treatment water. However, when passed through dental units, no significant bacterial reduction was achieved for samples of tap water (Group 1), tap water treated with bleach (Group 2), or tap water treated with Bio2000 (Group 4). Only water samples from dental units using Bio2000 alone (Group 3) or a combination of sterile, distilled water with Bio2000 (Group 5) met or exceeded the $200 \mathrm{CFU} / \mathrm{mL}$ standard.

(c) Seer Publishing 
Conclusions: Using tap water alone or tap water with bleach did not improve water quality. However, the American Dental Association (ADA) standard for reduced microbial contamination of dental unit waterlines was met using Bio2000 and distilled water treated with Bio2000.

Clinical Significance: The ADA standard of $200 \mathrm{CFU} / \mathrm{mL}$ was achieved using a closed water system and distilled water treated with Bio2000. Using 100\% Bio2000 is also effective, but more costly.

Keywords: Antimicrobial, bleach, chlorhexidine gluconate, dental treatment water, disinfection, dental unit waterlines (DUWL), waterlines, water quality

Citation: Kettering JD, Stephens JD, Muñoz-Viveros CA, et. al. Reducing Bacterial Counts in Dental Unit Waterlines: Tap Water versus Distilled Water. J Contemp Dent Pract 2002 August;(3)3: 001-009.

\section{Background}

The presence of microbial contamination of the water coming from dental units was first reported by Blake in $1963 .{ }^{1}$ In the years since that discovery, research has been ongoing to identify potential bacterial human pathogens from dental unit waterlines (DUWL). ${ }^{2-9}$ At the same time, studies have assessed the efficacy of different products and techniques to reduce, if not eliminate, microbial levels in dental treatment water. ${ }^{3-9}$

While no apparent widespread nosocomial infections in dental patients have been directly attributed to dental treatment water, concerns center on the exposure of immunocompromised patients or individuals who receive dental treatment while undergoing immunosuppressive chemotherapy to potentially harmful microorganisms. ${ }^{3,4}$ Mills reported two civil suits in which separate plaintiffs claimed their medical conditions (bacterial endocarditis and a brain abscess) resulted from exposure to contaminated dental treatment water. ${ }^{3}$ In the case of bacterial endocarditis, the same strain of gram-negative water bacteria (Moraxella) was isolated from both the patient and the dental unit waterlines. The brain abscess case was mentioned on the television program, "CBS Morning News," but no details were discussed. Both cases were settled out of court and without the benefit of scientific investigation, according to Mills. $^{3}$

Some of the opportunistic pathogens identified in dental treatment water include Pseudomonas, Moraxella, Klebsiella, or other primary environmental organisms such as Legionella and Myco-
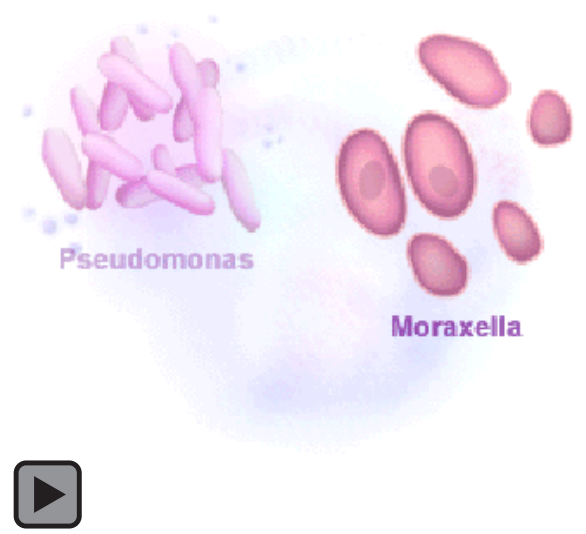

bacterium. ${ }^{4.8}$ On a broader level, there is a general desire among dental professionals to assure patients the dental treatment water is monitored to ensure it is as safe, or safer, than public drinking water. Cleansing techniques (flushing) are helpful adjuncts, but such treatments alone are not effective in achieving the $200 \mathrm{CFU} / \mathrm{ml}$ standard. ${ }^{9}$ Bacteria attach to surfaces aggregate in a hydrated polymeric matrix of their own synthesis to form biofilms. The pattern of development involves initial attachment to a solid surface. This is followed by the formation of microcolonies on the surface and, finally, the differentation into exopolysaccharide-encased microcolonies resulting in mature biofilms. Plaque is a naturally constructed biofilm, with approximately $60 \%$ to $70 \%$ of its volume made up of bacterial cells, mostly gram-positive cocci and filamentous forms. The microbial accumulations in plaque subject the teeth and gingival tissues to high concentrations of bacterial metabolites that may result in dental disease. Planktonic bacteria may be cleared by antibodies and phagocytes and are susceptible to antibiotics. Adherent bacteria in biofilms are resistant to phagocytosis 
but phagocytic enzymes are released. These enzymes may damage tissue around the biofilm, and planktonic bacteria are released from the biofilm. This release may cause dissemination and acute infection in neighboring tissues.

Flushing waterlines with water for 5, 10, 15, and even 20 minutes cannot achieve consistent reductions below the American Dental Association (ADA) standard, even with the addition of 2.5 parts per million (ppm) of chlorine (bleach). ${ }^{10}$ In fact, a number of chemical agents have been evaluated for use in disinfecting DUWLs to Include: sodium fluoride, Listerine ${ }^{\circledast}$ mouth rinse, hydrogen peroxide $\left(\mathrm{H}_{2} \mathrm{O}_{2}\right)$, household bleach (sodium hypochlorite), and chlorhexidine gluconate. ${ }_{14}$ Studies of dental unit waterline contamination have been influenced by factors such as: (1) water source selection for disinfection (tap water versus distilled water), (2) the type of system (an open system drawing tap water versus a closed systems using bottled, distilled water), and (3) whether or not antimicrobial agents, such as those previously listed, were added to the water source.

In a 2000 cover story article published in the Journal of the American Dental Association, Mills ${ }^{3}$ reviewed several options available to improve the quality of dental treatment water by reducing the number of colony-forming units. The author was quick to point out ".... lack of consensus among the experts about the best approaches to solving the problem."3

A number of studies involving dental treatment water quality have focused on two principal issues: (1) reducing the microbial count of water samples to or below the 200 colony forming units per millileter (CFU/mL) standard recommended by the ADA in $1996{ }^{4}$ and (2) identifying effective mechanical techniques and chemical disinfectants for treating dental unit waterlines. ${ }^{2-6}$

Consensus or no consensus, clinicians, clinics, and dental schools provide a wide variety of dental services to a growing number of patients each day. Moreover, they all share a common goal to maintain or improve the quality of their dental treatment water as part of their overall infection control protocol. So they need definitive guidance on the management of microbial contamination and the maintenance of safe dental treatment water. In this way, they can be assured both their patients and staff members are appropriately pro- tected from any potential microbial contamination resulting from the use of untreated dental treatment water.

In an effort to address these issues, a study was undertaken to evaluate three critical issues: (1) the type of water source to use (tap water vs. sterile distilled water), (2) the impact of dental unit design with the use of an open (municipal water) supply vs. a closed (bottled) water source on waterline contamination and treatment, and (3) the role and effectiveness of antimicrobial flushes in dental unit waterlines.

\section{Materials and Methods}

A total of 75 new dental units with a closed-circuit water system (Adec, model Decade 1021) were used in this study. Water samples were collected from the air/water syringe and the high-speed handpiece waterlines at baseline, four, and six weeks. Before the start of the study, the water bottle containers of each dental unit were sterilized. The day samples were collected from the waterlines, the lines were flushed for 30 seconds, and approximately 50 milliliters $(\mathrm{ml})$ of water were collected in a sterile, plastic container. All the samples were collected at Noon. When the collection was done, no handpiece or syringe tip was used, because the authors did not want to introduce another potential source of contamination and/or variable. For all units, except Group 2, the waterlines were filled with solution, left overnight, and then flushed for 30 seconds in the morning prior to patient treatment. Careful attention was paid to avoid possible contamination of the water when the samples were collected. The water samples were immediately sent to the microbiology laboratory after collection.

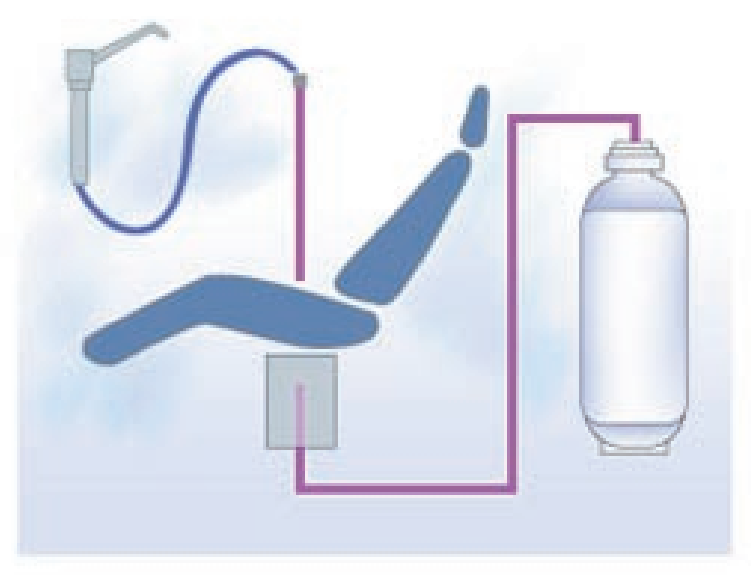


Fifteen dental units were assigned to one of five treatment groups in the following manner:

Group 1: Bottles were filled and used with tap water only (untreated controls). No further treatment was done to these units.

Group 2: Same treatment as Group 1 only that at the end of every week, a $5.25 \%$ sodium hypochlorite (bleach) dilution flush was used. [The dilution was prepared using 1 cup or 8 fluid ounces of $5.25 \%$ sodium hypochlorite (bleach) diluted in 1 gallon of water or 128 fluid ounces or $0.31 \%$ dilution. The total dilution was $0.31 \%]$. One fluid ounce of the dilution was placed in the bottle and the handpiece and air/water syringe lines were flushed for 5 seconds until the lines were filled with the dilution. The solution was left in the lines for 10 minutes and then flushed for 2 minutes with tap water. The treatment was repeated every week. The bleach solution was not left overnight, because the manufacturer of the chairs (Adec) does not recommend an overnight treatment.

Group 3: Bottles were filled and used with 100\% $0.12 \%$ chlorhexidine gluconate (Bio2000). No further treatment was done to these units. (Bio2000, now marketed under the name of BioBLUE, is manufactured by Micrylium Laboratories, Inc, Phoenix, AZ).

Group 4: Bottles were filled with tap water. At the end of the day, the tap water was discarded, the bottles were filled with one fluid once of $0.12 \%$ chlorhexidine gluconate, and the handpiece and air/water syringe lines were flushed for 5 seconds until the lines were filled with the solution. The solution was left in the waterlines overnight. The next day the units were flushed with tap water for 2 minutes.

Group 5: Bottles were filled with sterile distilled water (Arrowhead Mountain Spring Water Company, Greenwich, CT). At the end of the day, the distilled water was discarded and the bottles were filled with one fluid ounce of $0.12 \%$ chlorhexidine gluconate; the handpiece and air/water syringe lines were flushed for 5 seconds until the lines were filled with the solution. The solution was left in the waterlines overnight. The next day the unit waterlines were flushed with distilled water for 2 minutes. At Noon-time, water samples of approximately 50 milliliters $(\mathrm{ml})$ in volume were collected in sterile, plastic specimen containers from both the air/water syringe and the handpiece waterline. These samples were gathered at baseline (0 time), two weeks, four weeks, and again at six weeks. The microbial culturing protocol described below was followed:

\section{Microbial Culturing Protocol}

Each water container was labeled, but coded so the evaluators were blinded to its contents. The labeled water samples were mixed by vortexing for 30 seconds. Fifty microliters of liquid were removed and added to 100 milliliters of sterile, deionized water (Suspension 1). One hundred microliters were removed from Suspension 1 and added to a second 100 milliliters of sterile water (Suspension 2). Each addition was mixed thoroughly. The 100-ml suspensions were filtered through separate $47 \mathrm{~mm}$ membrane filters (MicroFunnel, Gelman Sciences, Ann Arbor, MI), and the filters were removed aseptically to a sterile R2A agar plate (R2A Agar, Difco, Becton Dickinson Microbiology Systems, Sparks, MD). The plates were incubated at room temperature for five days. Bacterial colonies were counted and dilution factors applied (20 for Suspension 1 and 2000 for Suspension 2) to obtain CFU/mL values.

The municipal water supply to Loma Linda University School of Dentistry, which is routinely sampled by the City of Loma Linda, CA, was also evaluated, because it was the source of the tap water. Water testing was performed by an independent laboratory under contract by the city of Loma Linda. Water was collected at a standard location in the dental school, analyzed, and the data were obtained from them in an official report. A total of seven samples were taken at one-week intervals, and those specimens were sent to a commercial laboratory licensed in the State of California for water analysis.

\section{Statistical Methods}

A one-way analysis of variance (ANOVA) was performed to evaluate the change in CFU/mL over time for each of the five treatment groups $(\mathrm{P}<0.05)$. When differences were found, a Student-Newman-Kuels all pairwise multiple comparison was used to identify those differences. 
Table 1. Bacterial Counts from Samples of City Water Supply

$\begin{array}{ccc}\begin{array}{c}\text { Sample Processed } \\ \text { Sample \#1 }\end{array} & \begin{array}{c}\text { Colony Forming Units (CFU/ } \\ \mathbf{m L})^{*}\end{array} & \text { Coliform Test } \\ \text { Sample \#2 } & 4 & \text { Negative } \\ \text { Sample \#3 } & 10 & \text { Negative } \\ \text { Sample \#4 } & 30 & \text { Negative } \\ \text { Sample } \# 5 & 90 & \text { Negative } \\ \text { Sample } \# 6 & 95 & \text { Negative } \\ \text { Sample } \# & 25 & \text { Negative } \\ \text { "All counts within acceptable range of < 500 CFU/mL as per the standard for safe drinking } \\ \text { water (Safe Drinking Water Act of 1999). The samples were collected at the same location } \\ \text { in the School Dentistry over a seven-week period. }\end{array}$

Table 2. Air/water syringe and high-speed handpiece waterline counts (CFU/ml)

\begin{tabular}{|c|c|c|c|c|c|c|c|c|c|}
\hline & & \multicolumn{2}{|c|}{ Baseline } & \multicolumn{2}{|c|}{ Weak 2} & \multicolumn{2}{|c|}{ Week 4} & \multicolumn{2}{|c|}{ Week 6} \\
\hline & & Mean & SD & Mean & SD & Mean & SD & Mean & SD \\
\hline Groups & $\begin{array}{l}\text { Air/water } \\
\text { syringe }\end{array}$ & & & & & & & & \\
\hline 1 & Tap Water & 781 & 72 & 6413750 & 2842306 & 5861538 & 3352635 & 6447500 & 2806144 \\
\hline 2 & $\begin{array}{l}\text { Tap water/ } \\
\text { Bleach }\end{array}$ & 340 & 0 & 7078667 & 2434989 & 6012252 & 3433724 & 6910000 & 2771734 \\
\hline 3 & Bio 2000 & 89 & 0 & 0 & 0 & 1449 & 5139 & 0 & 0 \\
\hline 4 & $\begin{array}{c}\text { Tap waterl } \\
\text { Bio2000 }\end{array}$ & 80 & 0 & 5530668 & 3644366 & 626000 & 3063595 & 6500360 & 3121696 \\
\hline \multirow[t]{2}{*}{5} & $\begin{array}{l}\text { Distilled/ } \\
\text { Bio2000 }\end{array}$ & 217 & 199 & 202 & 207 & 100 & 135 & 17 & 39 \\
\hline & Handpiece & & & & & & & & \\
\hline 1 & Tap Water & 762 & 117 & 7177333 & 2174171 & 7511667 & 1691636 & 7430667 & 1719051 \\
\hline 2 & $\begin{array}{l}\text { Tap water/ } \\
\text { Bleach }\end{array}$ & 689 & 0 & 7197333 & 2124172 & 6184047 & 3207414 & 7111429 & 2258832 \\
\hline 3 & Bio2000 & 80 & 0 & 0 & 0 & 18808 & 72257 & 0 & 0 \\
\hline 4 & $\begin{array}{c}\text { Tap waterl } \\
\text { Bio2000 }\end{array}$ & 800 & 0 & 6682667 & 2789663 & 6158667 & 3175896 & 6474667 & 3163032 \\
\hline 5 & $\begin{array}{l}\text { Distilled/ } \\
\text { Bio2000 }\end{array}$ & 333 & 548 & 100 & 135 & 33 & 78 & 0 & 0 \\
\hline
\end{tabular}

All differences were statistically significant or equal at a level of $P=0.001$ 
Figure 1: Air/Water Syringe Waterline

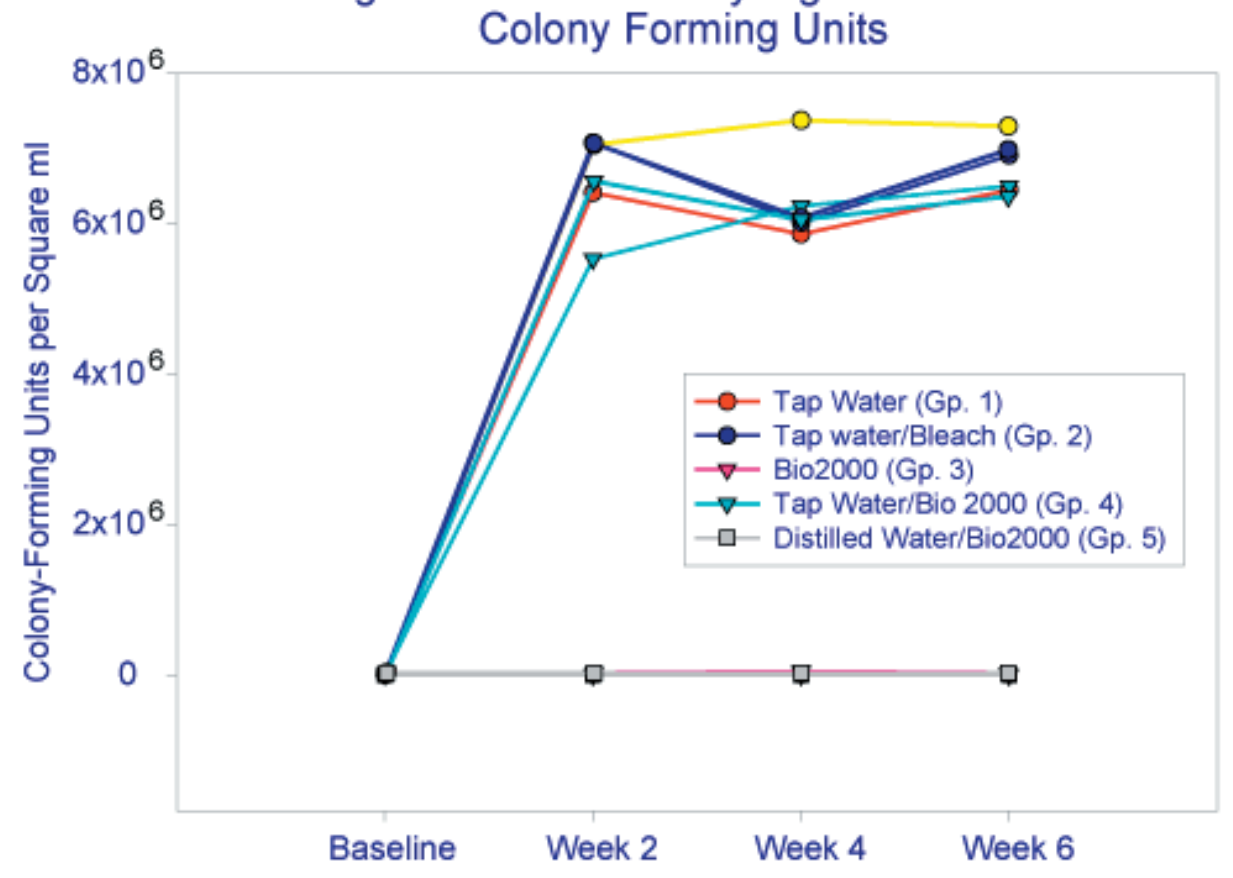

Figure 2: High Speed Hand-piece Dental

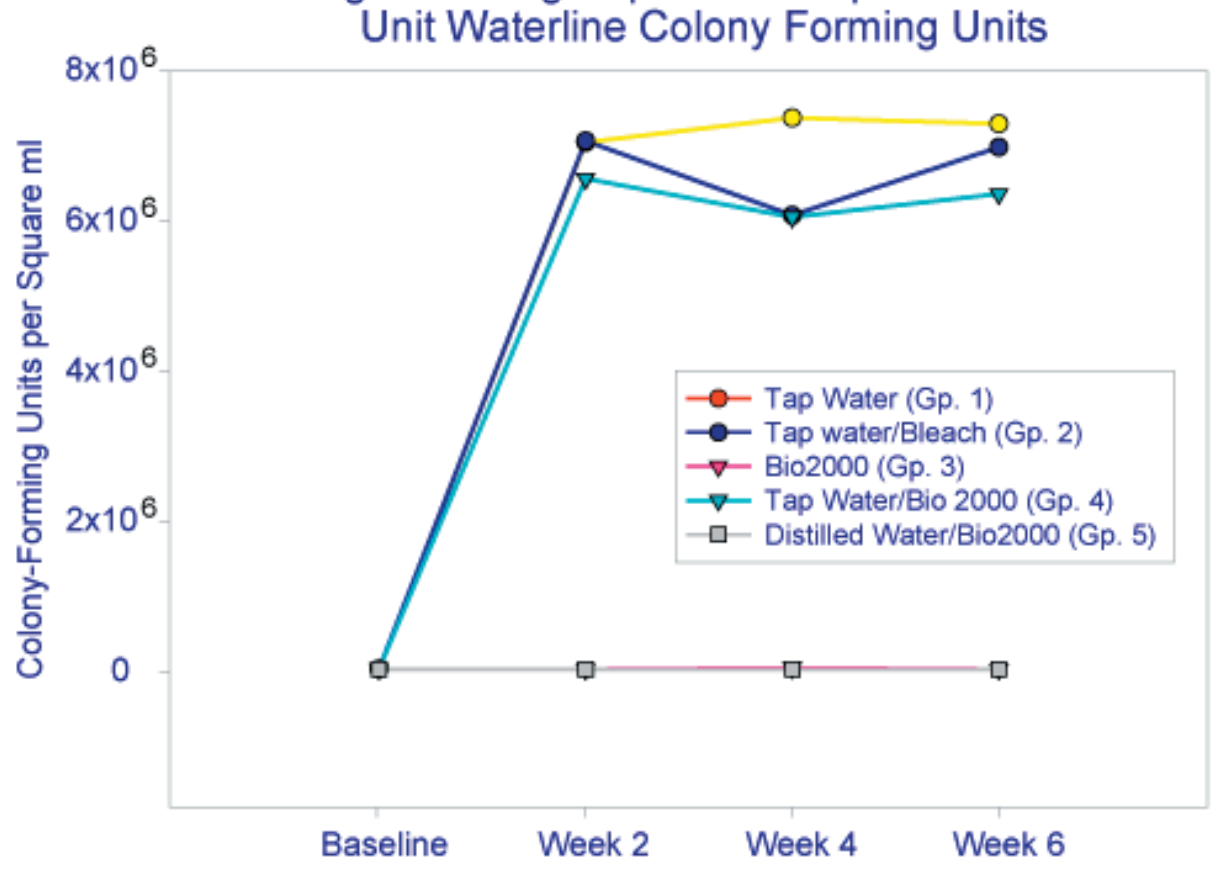




\section{Results}

The results of the municipal water analysis for the tap water are presented in Table $1 .{ }^{15}$ The microbial count of the seven tap water specimens ranged from 4 to $95 \mathrm{CFU} / \mathrm{mL}$. These values were well below the ADA waterline standard of $200 \mathrm{CFU} / \mathrm{mL}$ and the $500 \mathrm{CFU} / \mathrm{mL}$ level deemed acceptable for public drinking water. ${ }^{4,16}$ These outcomes served as baseline measures of the microbial level before the water was run through a functioning dental unit.

The study results for the comparison of outcomes for Groups 1 to 5 are presented in Table 2 and illustrated graphically in Figures 1 and 2. Note that both figures illustrate there was no significant reduction in the bacterial count using the protocols of Group 1 (tap water alone - control group), Groups 2 (tap water with weekly flush of $5.25 \%$ sodium hypochlorite dilution), or Group 4 (0.12\% chlorhexidine gluconate, Bio2000, and tap water). However, samples of chlorhexidine gluconate, Bio2000, either used solely (Group 3) or in combination with sterile distilled water (Group 5) did produce a statistically significant reduction of the colony forming units to or below the target level of $200 \mathrm{CFU} / \mathrm{mL}$. (Table 2) In fact, all counts for Groups 3 and 5 were well below the ADA recommended $200 \mathrm{CFU} / \mathrm{mL}$ standard, except for week 4 Bio2000, and this count returned to 0 at week 6 .

\section{Discussion}

This study was conducted to determine whether the type of water used to disinfect dental unit waterlines (tap water versus distilled water) had any significant impact on the efficacy of several different disinfection protocols. Based on the results of this study, it would appear that water source selection may indeed play a critical role in the entire process of disinfecting DUWLs.

Unto itself, the community tap water apparently had relatively low mesophilic heterotrophic microbial levels initially with samples ranging from a mere $4 \mathrm{CFU} / \mathrm{mL}$ to as many as $95 \mathrm{CFU} / \mathrm{mL}$ (see Table 1). But even the introduction of chemical disinfectants, such as $5.25 \%$ sodium hypochlorite dilution in Group 2 or $0.12 \%$ chlorhexidine gluconate in Group 4, could not prevent or eliminate microbial proliferation in tap water used in dental unit waterlines whether that disinfectant treatment was weekly (Group 2) or daily (Group 4).
Yet, the $0.12 \%$ chlorhexidine gluconate product used alone (Group 3) or combined with sterile distilled water (Group 5) did achieve waterline disinfection below the recommended $200 \mathrm{CFU} / \mathrm{mL}$ standard when the DUWLs were treated daily with each treatment protocol. Even when tap water was combined with $0.12 \%$ chlorhexidine gluconate (Group 4), the ADA standard could not be attained. (Table 2) The principal difference in these outcomes for the five test groups was in the type of water used in the dental unit waterlines (tap water versus sterile distilled water). It should be noted the sterile distilled water used in this study came from a commercial water company and was not distilled on the premises. The commercial water is steam distilled and similar to sterile water. Distilled water made in some dental offices still contains high bacterial counts.

Further support to the conclusion that water source selection may play a pivotal role in this process was evidenced by the outcome achieved by Group 5 (sterile distilled water with $0.12 \%$ chlorhexidine gluconate). All the Group 5 samples readily attained waterline disinfection below the $200 \mathrm{CFU} / \mathrm{ml}$ standard when sterile distilled water was mixed with $0.12 \%$ chlorhexidine gluconate in a daily treatment protocol of the dental unit waterlines.

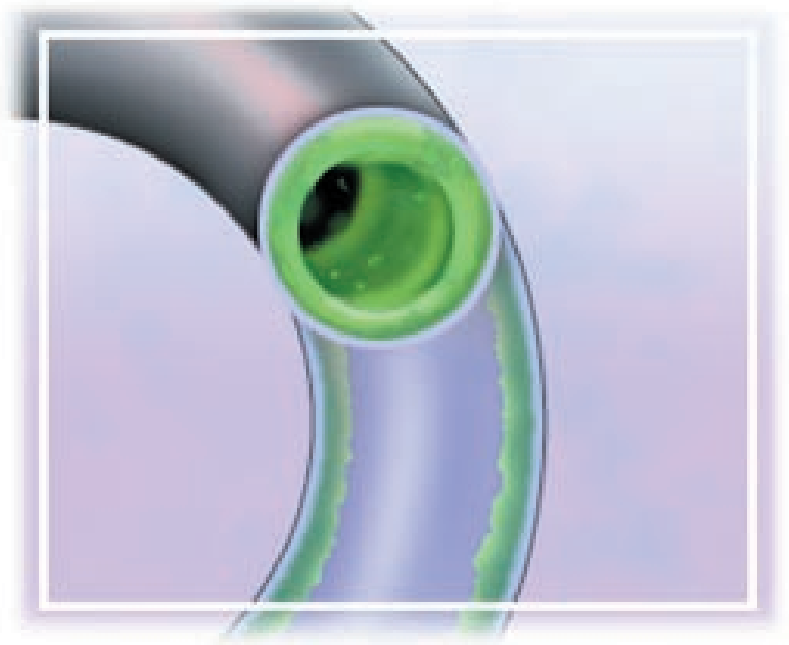

It is a matter of conjecture as to why the tap water samples had such unsatisfactory results. In evaluating these outcomes and after reviewing previously published reports, it was concluded the dark, damp, and warm interior of dental unit waterlines may serve an ideal incubator for bacterial proliferation.17 Although tap water may introduce an 
initial contamination level of 4 to $95 \mathrm{CFU} / \mathrm{mL}$ over the course of a day's routine use, the number of microorganisms can grow exponentially and readily exceed the $200 \mathrm{CFU} / \mathrm{mL}$ standard. The results of this study suggest that sterile, distilled water in combination with $0.12 \%$ chlorhexidine gluconate (Group 5) or $100 \% 0.12 \%$ chlorhexidine gluconate (Group 3) may be more appropriate treatments to achieve the ADA standard for dental treatment water than a regime involving municipal water supplies.

Conversely, pairing distilled water with that same chemical disinfectant $(0.12 \%$ chlorhexidine gluconate) in the daily treatment protocol used in this study did reduce microbial contamination to a level well within the recommended ADA standard. Of course, careful preparation and handling of this distilled water-disinfectant mixture is essential to prevent inadvertent contamination of the water source and the reservoir water bottle. This inadvertent contamination can be seen in Table 2 , on week 4 of the study. The handpiece waterline indicated there was microbial contamination of over $18,000 \mathrm{CFU} / \mathrm{ml}$ for one of the units, but the level dropped to 0 at week 6 . The source of the contamination is not known, but we presumed it occurred during water collection or the tube that goes in the bottle reservoir might have been touched, accidentally contaminating the sample.

The results from the first part of this investigation demonstrated that water source selection plays an important role in achieving and maintaining consistent disinfection of the dental unit waterlines. However, it was unclear if the outcome achieved by using $0.12 \%$ chlorhexidine gluconate (Bio2000) in Groups 3 and 5 was due to this specific product or whether other chemical antimicrobial agents could achieve a similar outcome. So a second investigation was undertaken to address this specific question. Is the type of chemical disinfectant used more critical than the water source selection (tap water versus sterile distilled water)? A subsequent study will report the results of testing the same dental units using five commercially available disinfectants mixed with distilled water in a closed water system.

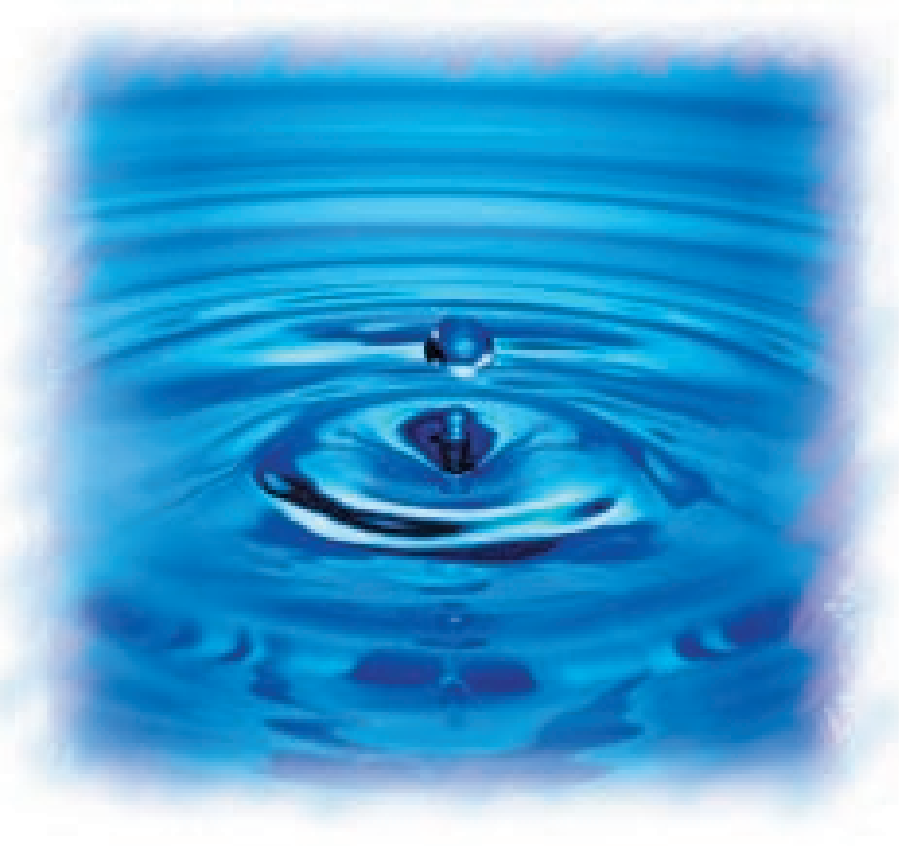

\section{Conclusions}

Based on the testing format and the materials used in this study, the following conclusions were drawn:

1. Tap water, even with apparent low levels of contamination, should not be used as a water source for dental unit waterlines.

2. Disinfection of dental unit waterlines can be achieved leaving one ounce of $0.12 \%$ chlorhexidine gluconate in the DUWLs overnight, followed by a daily two-minute flush with sterile distilled water each morning.

3. Dental units with a closed-water system did not meet the ADA standard of $200 \mathrm{CFU} / \mathrm{mL}$ when tap water was used alone or combined with a $0.12 \%$ chlorhexidine gluconate flush.

4. Dental units with a closed-water system did meet the ADA standard of $200 \mathrm{CFU} / \mathrm{mL}$ when a mixture of sterile distilled water and $0.12 \%$ chlorhexidine gluconate was allowed to remain in the dental unit waterlines overnight, followed by a two-minute morning flush with sterile distilled water. It would appear that water source selection (tap water versus sterile distilled water) may be critical to achieving the ADA standard of $200 \mathrm{CFU} / \mathrm{mL}$ or less. 


\section{References}

Note: Links to citations open in a new browser window. To return to this page, just close the newly opened browser window by clicking on the $\mathrm{X}$ in the upper right hand corner of the window.

1. Blake GC. The incidence and control of bacterial infection of dental unit and ultrasonic scales. $\mathrm{Br}$ Dent J 1963;15:413-6.

2. Williams JF, Johnston AM, Johnson B, et. al. Microbial contamination of dental unit waterlines: prevalence, intensity and microbiological characteristics. J Am Dent Assoc. 1993 Oct;124(10):59-65.

3. Mills SE. The dental unit waterline controversy: defusing the myths, defining the solutions. J Am Dent Assoc. 2000 Oct;131(10):1427-41. Review.

4. Shearer BG. Biofilm and the dental office. J Am Dent Assoc. 1996 Feb;127(2):181-9. Review.

5. Miller $\mathrm{CH}$. Microbes in the dental unit water. J Calif Dent Assoc. 1996 Jan;24(1):47-52. Review.

6. Kono G. The dental waterline controversy. Dent Today. 1996 Aug;15(8):82-5. Review. No abstract available.

7. Atlas RM, Williams JF, Huntington MK. Legionella contamination of dental-unit waters. Appl Environ Microbiol. 1995 Apr;61(4):1208-13.

8. Jensen ET, Giwercman B, Ojeniyi B, et al. Epidemiology of Pseudomonas aeruginosa in cystic fibrosis and the possible role of contamination by dental equipment. J Hosp Infect. 1997 Jun;36(2): 117-22.

9. Santiago Jl, Huntington MK, Johnson AM, et al. Microbial contamination of dental unit waterlines: short- and long-term effects of flushing. Gen Dent 1994;48: 528-44.

10. Karpay RI, Puttaiah R, Mills SE, et al. Efficacy of Flushing Dental Units for Different time Periods. (IADR abstract 3366) J Dent Res 1997;76:434.

11. Williams HN, Kelley J, Folineo D, et. al. Assessing microbial contamination in clean dental units and compliance with disinfection protocol. J Am Dent Assoc. 1994 Sep;125(9):1205-11.

12. Kettering J, Muñoz C, Stephens J, et al. Comparison of methods for reducing dental unit waterline bacteria and biofilm. Abstract (AADR abstract 3371). J Dent Res 1997;76:435.

13. Murdoch-Kinch CA, Andrews NL, Atwan S, et al. Comparison of dental water quality management procedures. J Am Dent Assoc. 1997 Sep;128(9):1235-43.

14. Meiller TF, DePaola LG, Kelley JI, et. al. Dental unit waterlines: biofilms, disinfection and recurrence. J Am Dent Assoc. 1999 Jan;130(1):65-72.

15. Kettering J, Stephens J, Muñoz CA. Use of antimicrobial rinses for reducing bacterial counts in dental unit waterlines. (AADR abstract 287). J Dent Res 1998;77(A):141.

16. American Public Health Association. Standard methods for the examination of water and wastewater. 20th ed. In: Easton AD, Clersceri LS, Greenberg AE, eds. Washington, American Public Health Association; 1999.

17. Costerton JW, Lewandowski Z, Caldwell DE, et. al. Microbial biofilms. Annu Rev Microbiol. 1995;49:711-45. Review. 


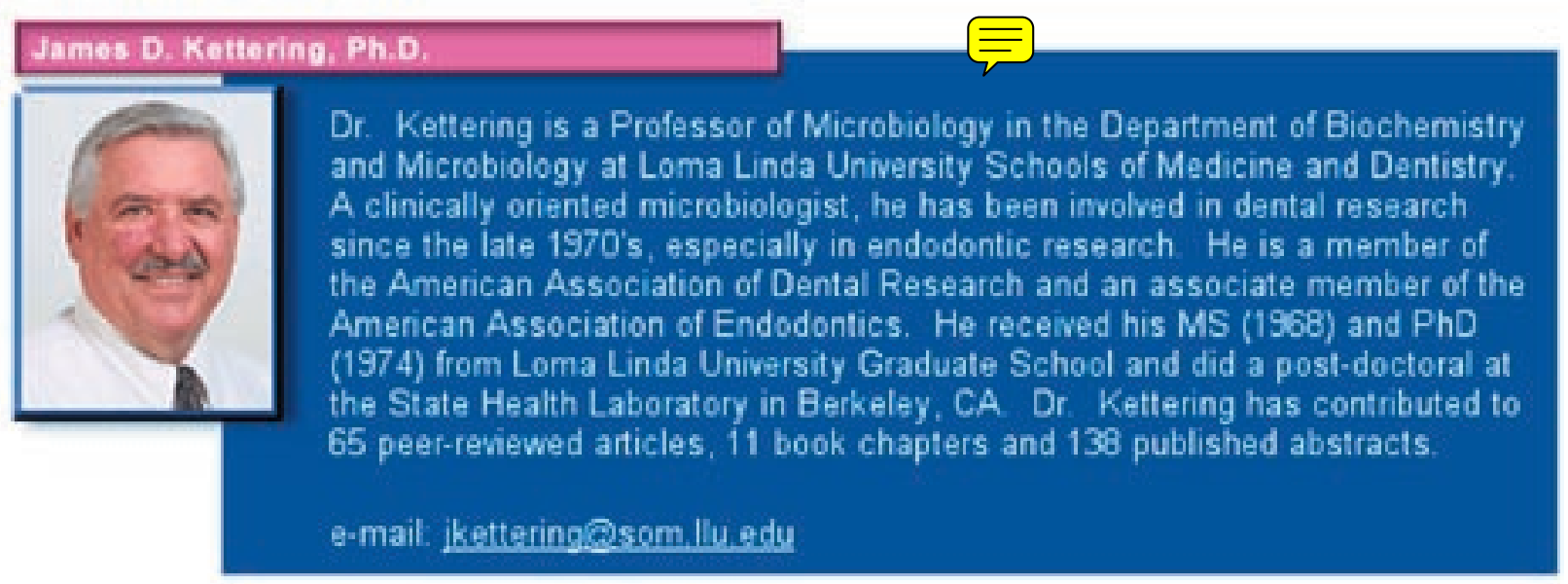

\section{Jonl A. Stophens, R.D.H., Ed. $\mathbf{3}$.}

Joni Stephens is an Associate Professor of Dental Hygiene in the School of
dentistry at Loma Linda University. She received her Dental Hygiane
education from Loma Linda Unversity. Loma Linda CA and her Master in
Education from Columbia University. $>$ From 1982 to July 1993, Ms. Stephens
served as Chair of the Dental Hygiene program. She is currently Director of
the undergraduate Research Mentorship Program for the Hygiene and Dental
students. Her research interests include dental unit waterines, disinfectants
and caries prevention. She is member of several national and international
dental and hygiene organizations.

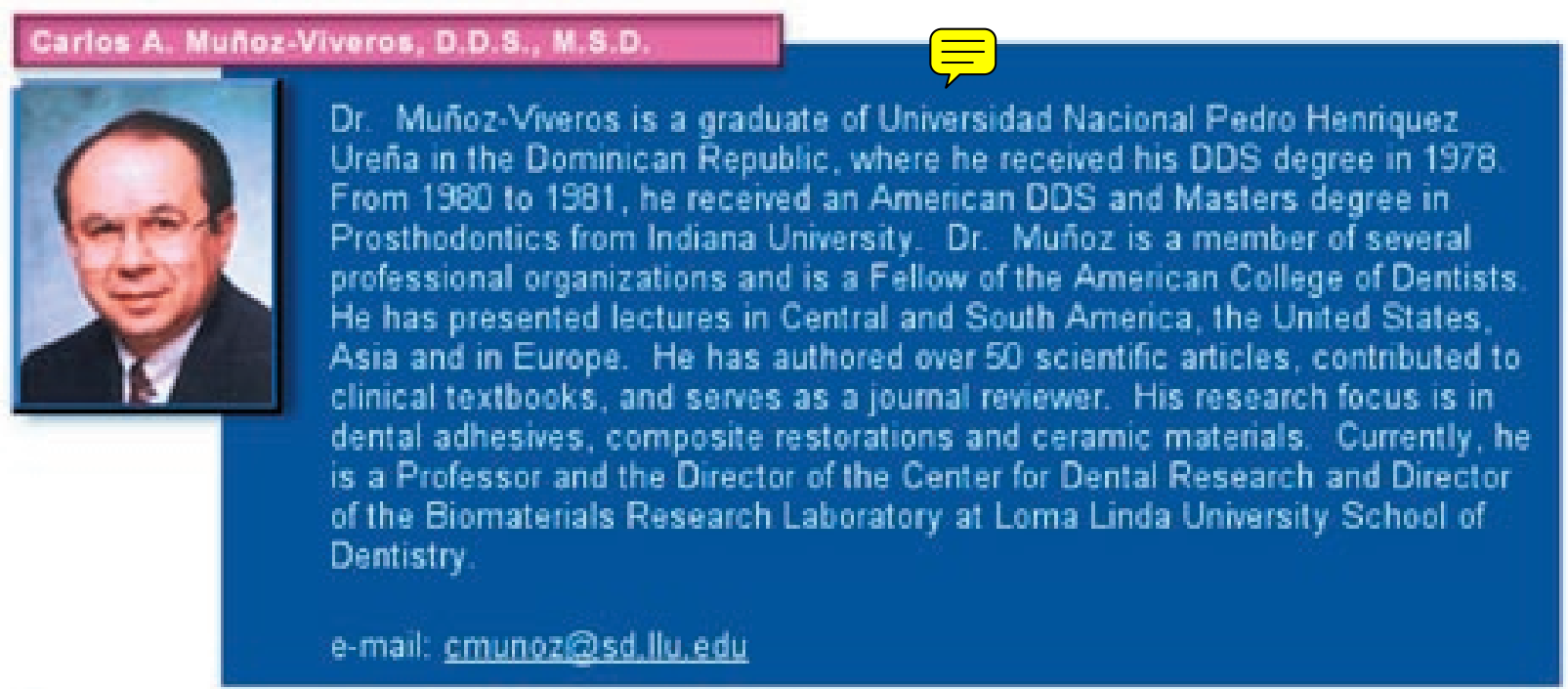




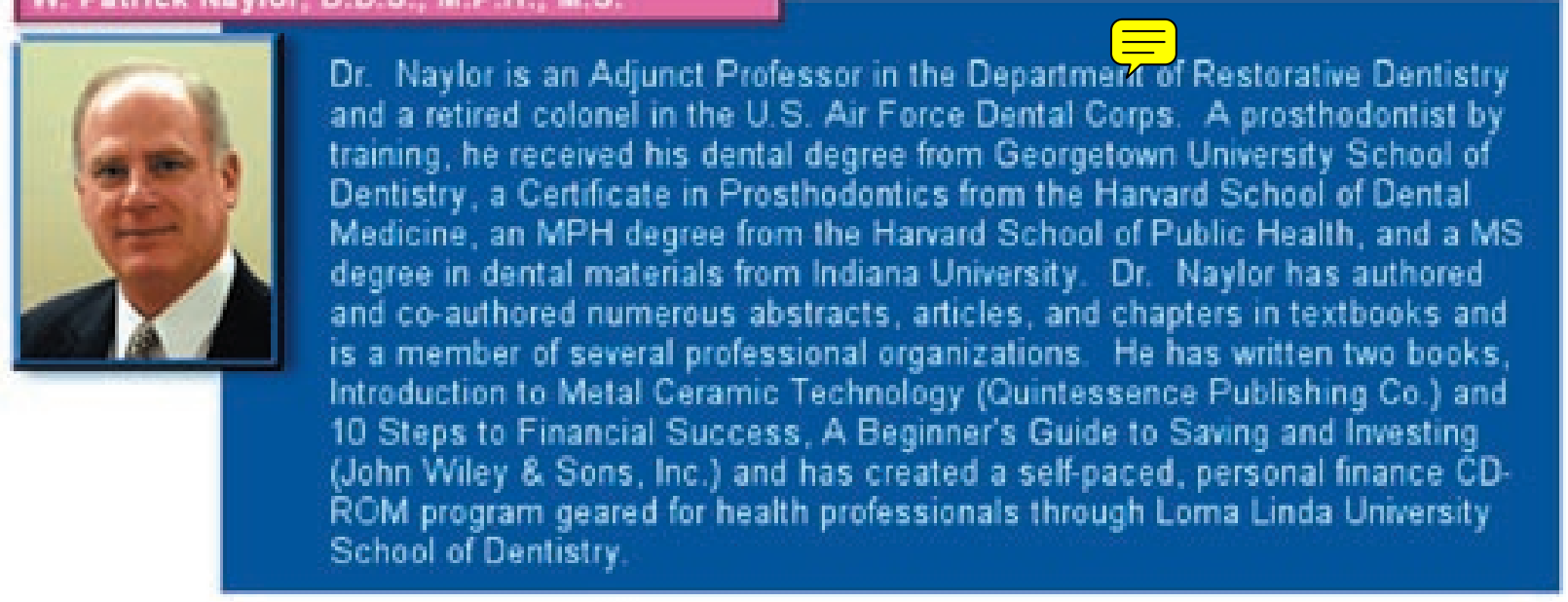

